\title{
Role of liver-X-receptors in airway remodeling in mice with chronic allergic asthma
}

\author{
JINMEI ZHANG ${ }^{1 *}$, ZHENGCAN WU ${ }^{2^{*}}$, FENFANG YU ${ }^{1^{*}}$, \\ LIANG YE $^{1}$, WEI GU ${ }^{1}$, YAN TAN ${ }^{1}$, LI WANG ${ }^{1}$ and YING SHI ${ }^{1}$ \\ Departments of ${ }^{1}$ Respiratory Medicine and ${ }^{2}$ Radiology, Nanjing First Hospital, \\ Nanjing Medical University, Nanjing, Jiangsu 210006, P.R. China
}

Received October 21, 2020; Accepted May 5, 2021

DOI: $10.3892 /$ etm.2021.10352

\begin{abstract}
Liver X receptors (LXRs) exert anti-inflammatory effects in animal models of certain respiratory diseases. In the present study, a model of chronic airway remodeling was established in wild-type and LXR-deficient mice. Ovalbumin (OVA)-sensitized mice were chronically administered OVA via inhalation for 8 weeks. Prior to each stimulation, certain wild-type mice were treated with GW3965, which is a highly selective LXR agonist. The influence of LXRs on airway inflammation, airway hyperresponsiveness and airway remodeling was evaluated. LXRs were indicated to increase airway inflammation and airway hyperresponsiveness, as well as promote airway remodeling. These results suggest that inhibiting LXRs may be a potential method for the treatment of allergic asthma.
\end{abstract}

\section{Introduction}

Asthma is a highly prevalent chronic airway disease, which affects $>300$ million individuals worldwide (1). Its morbidity and mortality rate are increasing gradually with the development of the society. The symptoms include shortness of breath, cough and chest tightness (2). To date, the pathological mechanisms of asthma have remained to be fully elucidated. Studies have indicated that the disease is an inflammatory disorder of the conducting airways, which has a strong association with allergic sensitization (3). It is classically recognized as a typical type 2 T-helper cell (Th2) disease, with increased immunoglobulin E ( $\mathrm{IgE}$ ) levels and eosinophilic inflammation in the airways. Resulting from airway inflammation, airway

Correspondence to: Dr Ying Shi, Department of Respiratory Medicine, Nanjing First Hospital, Nanjing Medical University, 68 Changle Road, Qinhuai, Nanjing, Jiangsu 210006, P.R. China E-mail:sykxss@163.com

${ }^{*}$ Contributed equally

Key words: liver $\mathrm{X}$ receptors, asthma, airway inflammation, airway hyperresponsiveness, airway remodeling remodeling leads to airway wall thickening and induces increased airway smooth muscle mass, which generates asthmatic symptoms (4). Chronic airway inflammation, airway hyperresponsiveness and airway remodeling are the central pathogenic processes of this disease (5).

Liver X receptors (LXRs) belong to the nuclear receptor superfamily and occur in two forms, known as $\operatorname{LXR} \alpha$ and LXR $\beta$ (6). Previous studies have established LXRs as the key modulators of both lipid metabolism and inflammation (7-10). When combined with natural ligands, such as oxysterols ordesmosterol (11), or synthetic ligands, including GW3965 or T0901317 (12), LXRs regulate the transcription of genes involved in cholesterol efflux and macrophage-mediated inflammation. The LXR ligand exertsinhibitory roles in lipopolysaccharide-induced lung inflammatory responses and anti-proliferative effects on airway smooth muscle (13-16). However, LXRs fail to attenuate acute allergic airway inflammation and Th2 cytokines in bronchoalveolar lavage fluid (BALF) (17). In chronic allergic asthma, LXRs have the ability to reduce serum IgE. Furthermore, the LXR agonist T0901317 is able to inhibit the airway remodeling process $(12,18,19)$. However, T0901317 is not highly selective for LXRs and it isalso able to activate other nuclear receptors, such as the Farnesoid X receptor $(20,21)$. To the best of our knowledge, there are currently no data regarding chronic allergic asthma in LXR-deficient mice. Therefore, it was necessary to performan in-depth study on this topic. Thus, the present study used LXR-deficient mice and a highly selective agonist of LXRs to investigate the role of LXRs in allergen-induced chronic asthma.

\section{Materials and methods}

Mice and ethics statement. A total of 36C57BL/6 female mice (age, 8 weeks; weight, $19 \pm 2 \mathrm{~g}$ ) were obtained from the Mice Breeding Service Department of GemPharmatech. Animals were given free access to sterilized tap water and a standard rodent chow in a specific pathogen-free biosafety level 3 facility at a temperature of $22-24^{\circ} \mathrm{C}$ and a relative humidity of $50-60 \%$. An artificial $12 \mathrm{~h}$ light/dark cycle with suitable ventilation was maintained in the animal room.

The present experiment was approved by The Institutional Animal Care and Use Committee of Nanjing First Hospital Affiliated to Nanjing Medical University Animal Center 
(Nanjing, China). Animal experiments were performed in strict accordance with the provisions of the Guidance on Feeding and Use of Experimental Animals by the Ministry of Science and Technology of the P.R. China. All operations were performed under anesthesia and all efforts were made to minimize suffering.

Establishment of the mouse model and drug intervention. Mice were randomly divided into six groups ( $\mathrm{n}=6$ mice/group) as follows: Control group, ovalbumin (OVA) group, GW3965 group, $\mathrm{LXR} \alpha^{-/}$group, $\mathrm{LXR} \beta^{-/}$group and $\mathrm{LXR} \alpha / \beta$ knockout (KO) group. Certainwild-type mice received intervention with the LXR agonist GW3965 (Cayman Chemical Company) at $20 \mathrm{mg} / \mathrm{kg}$ by intraperitoneal injection. LXR-KOmice and wild-type mice were used to establish a chronic asthma model (18). Mice were intraperitoneally injected with $0.1 \mathrm{ml}$ sensitizing solution [0.1 mg OVA; $0.07 \mathrm{ml} \mathrm{Imject}^{\mathrm{TM}}$ Alum Adjuvant (Beijing Biolead Biotechnology Co., Ltd.); $0.03 \mathrm{ml}$ PBS] on days 0,7 and 14 . The mice were stimulated with $1 \%$ OVA solution using an ultrasonicnebulizer (402AI; Jiangsu Yuyue Medical Equipment \& Supply Co., Ltd.) from day 21 for $30 \mathrm{~min}$ each time, three times a week, for 8 consecutive weeks. Mice treated with the LXR agonist were administered an intraperitoneal injection of GW3965 at $20 \mathrm{mg} / \mathrm{kg}(10,22)$ prior to each stimulation.

Airway physiology. Airway responsiveness was measured $24 \mathrm{~h}$ after the last OVA treatment using an AniRes 2005 Lung Function system (Bestlab). The mice were anesthetized with Nembutal (60 mg/kg; intraperitoneal). The trachea was then surgically exposed and connected to a computer-controlled ventilator using an intratracheal tube. The respiration rate and the expiratory/inspiratory time ratio were preset at 90/min, 1.5:1. Mice were stabilized for 5 min. Subsequently, various doses of acetylcholine chloridewere administeredby atomizing inhalation for $20 \mathrm{sec}$ at increasing concentrations, with intervals of $5 \mathrm{~min}$ from 10 to $200 \mu \mathrm{g} / \mathrm{kg}$. The values of airway resistance were recorded by the system after the administration of acetylcholine chloride (18).

Analysis of serum and BALF. After the airway physiology analysis, blood was collected from the hearts of the mice. The collected blood was left in a centrifuge tube at room temperature for $2 \mathrm{~h}$ and was centrifuged at 4,000 $\mathrm{x} \mathrm{g}$ for $10 \mathrm{~min}$ at $4^{\circ} \mathrm{C}$. The supernatant was transferred into a clean $1.5-\mathrm{ml}$ centrifuge tube and stored at $-80^{\circ} \mathrm{C}$. Mice were sacrificed by cervical dislocation. When the spinal cord and brain were severed, spontaneous respiration disappeared and there was no response to external stimuli, indicating that the mouse had died instantly. In order to obtain the BALF, ice-cold PBS $(0.5 \mathrm{ml})$ was infused into the lungs and withdrawn thrice via tracheal cannulation (total volume, $1.5 \mathrm{ml}$ ). The supernatant obtained from the BALF was stored at $-80^{\circ} \mathrm{C}$ for subsequent biochemical analysis. The levels of IL-4 (cat. no. JM-02448M2), IL-5 (cat. no. JM-11729M2) and IL-13 (cat. no. JM-02456M2) in the BALF and the level of IgE (cat. no. JM-02339M2) (all Jiangsu Jingmei Biotech, Co., Ltd.) in serum were quantified using ELISAs according to the manufacturer's protocols.
The total cell count and differential cell type count in BALF from the slides and the stains was performed using Wright-Giemsa stain (Nanjing KeyGen Biotech Co., Ltd.) were determined using an optical microscope (Olympus Corporation). In total, $\geq 200$ cells were counted for each mouse and were identified as macrophages, eosinophils, lymphocytes and neutrophils according to standard pathological morphology under x400 magnification.

Histology and Masson trichrome staining. After the BALF samples were obtained, the left lung tissue was fixed in $10 \%$ (v/v) neutral buffed formalin. The tissue was then embedded in paraffin, sectioned at $5-\mu \mathrm{m}$ thickness and subjected to $\mathrm{H} \& \mathrm{E}$ or periodic acid-Schiff (PAS) staining to estimate inflammation or mucus production, respectively. The numbers of PAS-negative and PAS-positive epithelial cells (goblet cells) in individual bronchioles were counted. In total, $\geq 10$ random bronchioles were counted in each slide.

The sections were then subjected to Masson trichrome staining to evaluate collagen deposition according to the standard protocol recommended by the manufacturer. All histologic examinations were performed in a double-blinded manner under x200 magnification.

Immunostaining for $\alpha$-smooth muscle actin ( $\alpha$-SMA). Immunohistochemistry was performedto detect $\alpha$-SMA. The paraffin slices were dewaxed inxylene followed by rehydration and were then incubated in $3 \% \mathrm{H}_{2} \mathrm{O}_{2}$ at room temperature for 10 min to eliminate the activity of endogenous peroxidase. Subsequently, the slices were rinsed with distilled water and soaked twice in PBS for $5 \mathrm{~min}$. These slices were blocked with $5 \%$ normal goat serum [Hangzhou Multisciences (Lianke) Biotech, Co., Ltd.] in PBS at room temperature for $10 \mathrm{~min}$, after which the serum was removed but slices were not washed. Next, the mouse anti-human $\alpha$-SMA monoclonal antibody (1:50 dilution; cat. no. GA085; Dako; Agilent Technologies, Inc.) was added and the slices were incubated for $2 \mathrm{~h}$ at $37^{\circ} \mathrm{C}$ or overnight at $4^{\circ} \mathrm{C}$. Following rinsing three times with $\mathrm{PBS}$ for $5 \mathrm{~min}$, a peroxidase-labeled goat anti-mouse polyclonal $\mathrm{IgG}$ antibody (1:1,000 dilution; cat. no. AP124ASigma-Aldrich; Merck KGaA) was added and the slices were incubated at $37^{\circ} \mathrm{C}$ for $30 \mathrm{~min}$. This was followed by rinsing with PBS and staining with diaminobenzidine at $-20^{\circ} \mathrm{C}$ for $5 \mathrm{~min}$. (Santa Cruz Biotechnology, Inc.). After washing, re-dyeingwith hematoxylin at $37^{\circ} \mathrm{C}$ for $5 \mathrm{~min}$ and dehydration, the slides were made transparent and sealed with neutral gum. Image Pro Plus 6.0 software (Media Cybernetics, Inc.) was used for analysis of the immunostained sections. Results werepresented as the area of $\alpha$-SMA immunostaining per $\mu \mathrm{m}$ length of the basement membrane of the bronchioles that had a 150-200 $\mu \mathrm{m}$ internal diameter. In total, $\geq 10$ bronchioles were randomly selected in each of the slides.

Statistical analysis. Values are expressed as the mean \pm standard error of the mean. Comparisons among the different groups were performed by one-way ANOVA (with nonparametric or mixed test) followed by Tukey's post-hoc test for multiple comparisons (GraphPad Prism 8.0). Statistical comparisons used SPSS 16.0 (SPSS, Inc.). P<0.05 was considered to indicate statistical significance. 


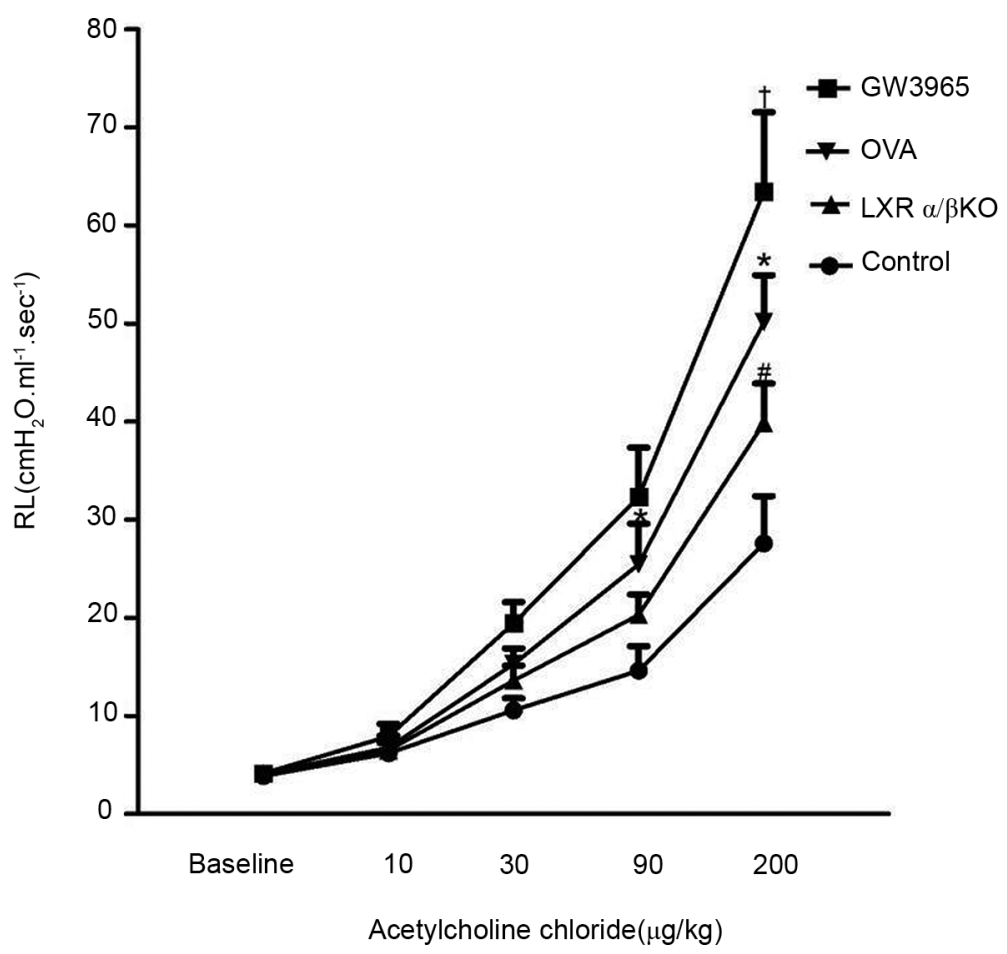

Figure 1. LXRs promote AHR in chronic asthmatic mice. LXR $\alpha / \beta$ KO mice displayed lower AHR, while the GW3965-treated mice displayed higher AHR compared with the mice in the OVA group. "P<0.05 OVA group vs. control group; ${ }^{\dagger} \mathrm{P}<0.05$ GW3965 group vs. OVA group; ${ }^{*} \mathrm{P}<0.05 \mathrm{LXR} \alpha / \beta \mathrm{KO}$ group vs. OVA group. AHR, airway hyperresponsiveness; LXR, liver X receptor; OVA, ovalbumin; RL, lung resistance; KO, knockout.

\section{Results}

LXRs increase airway hyperresponsiveness in the chronic model of asthma. After the administration of the indicated doses of aerosolized acetylcholine for $20 \mathrm{sec}$, at $24 \mathrm{~h}$ after the last OVA challenge, lung resistance (RL) was recorded (Fig. 1). There was no difference in basic airway resistance between the groups. Administration of acetylcholine induced a concentration-dependent increase in RL in each group. When the stimulation dose reached $200 \mu \mathrm{g} / \mathrm{kg}$, the airway resistance was higher in the GW3965 group compared with that in the OVA group $(\mathrm{P}<0.05)$. Furthermore, the airway resistance was lower in the LXR $\alpha / \beta$ KO group compared with that in the OVA group $(\mathrm{P}<0.05)$. However, there was no decrease in the RL of LXR $\alpha^{--}$and $\mathrm{LXR} \beta^{-/}$mice compared with that in the mice in the OVA group (data not shown).

Effect of LXRs on lung histology in the chronic model of asthma. Rare inflammatory cells were observedaround the airways in the control group. Furthermore, mice in the OVA group presented with severe infiltration of inflammatory cells around the respiratory tract and mice in the GW3965 group presented with a marked increase in inflammatory cells around the airways. In addition, $\mathrm{LXR}^{-/-}$mice and $\mathrm{LXR} \beta^{-/}$mice did not exhibit anyreduced OVA-induced inflammation of the airways. It was indicated that $\mathrm{LXR} \alpha / \beta \mathrm{KO}$ mice presented with reduced inflammation of the airways compared with mice in the OVA group (Fig. 2A-F).

Effect of LXRs on inflammatory cells in the BALF of the chronic model of asthma. Following sensitization and treatment challenges, the total number of leukocytes, as well as macrophages, eosinophils, lymphocytes and neutrophils in the BALF of the OVA group were significantly increased compared with those in the control group. It was indicated that treatment with GW3965 significantly enhanced the number of eosinophils and lymphocytes in the BALF compared with those in the OVA group. Furthermore, LXR $\alpha / \beta$ KO mice had fewer total leukocytes, macrophages, lymphocytes and eosinophils as compared with mice in the OVA group. However, there was no significant depression of inflammatory cells in the BALF of $\mathrm{LXR} \alpha^{-/}$mice and LXR $\beta^{-/}$mice compared with those in the OVA group (Fig. 3).

Effect of LXRs on IL-4, IL-5 and IL-13 levels in the BALF and IgE levels in serum of the chronic model of asthma. The levels of IL-4, IL-5 and IL-13 in the BALF and the levels of IgE in serum were quantified using ELISAs. The levels of IL-4, IL-5 and IL-13 in the BALF were significantly higher in the OVA group compared with those in the control group. Furthermore, the levels of the inflammatory cytokines were higher in the GW3965 group compared with those in the OVA group. However, the levels of these inflammatory cytokines were lower in the LXR $\alpha / \beta$ KO group compared with those in the OVA group. Compared with the control group, the OVA, GW3965 and LXR $\alpha / \beta$ KO groups had significantly higher IgE levels. The IgE levels in the LXR $\alpha / \beta$ KO group were significantly higher compared with those in the OVA group, while the GW3965 group had significantly lower levels (Fig. 4A-D).

LXRs inhibit airway remodeling in chronic experimental asthma. The level of airway metaplasia and mucus production was assessed via PAS staining of lung tissues (Fig. 5A-G). There was a low number of PAS-positive goblet cells in the control 


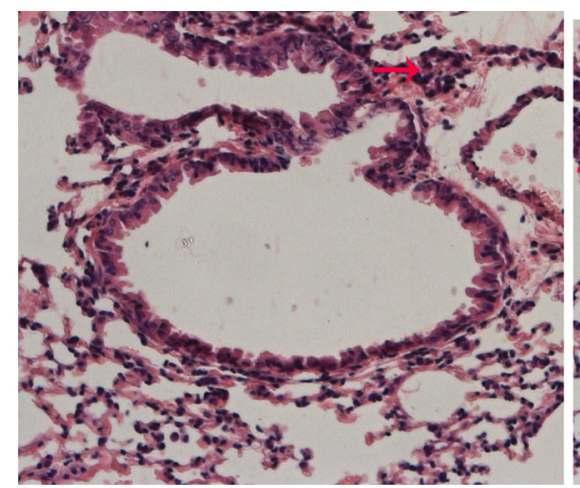

A

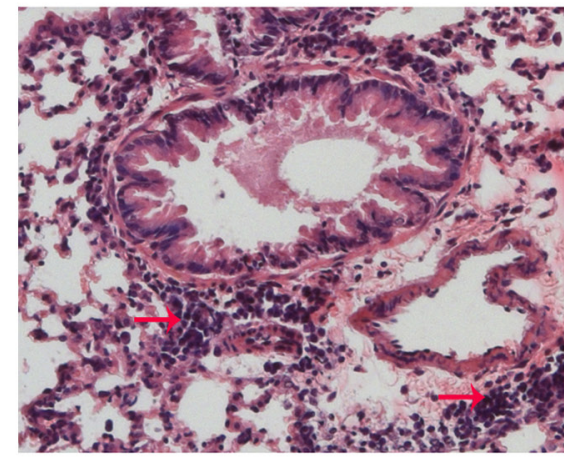

D

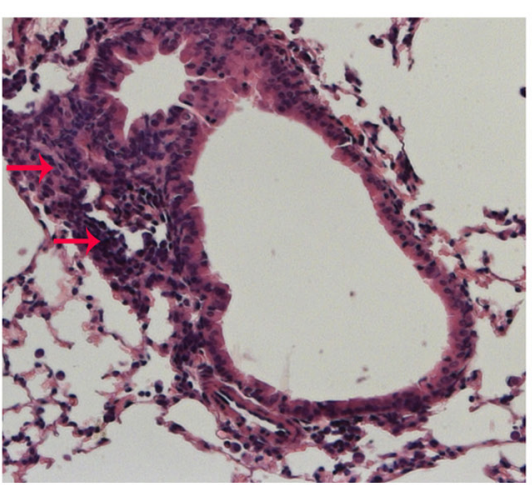

B

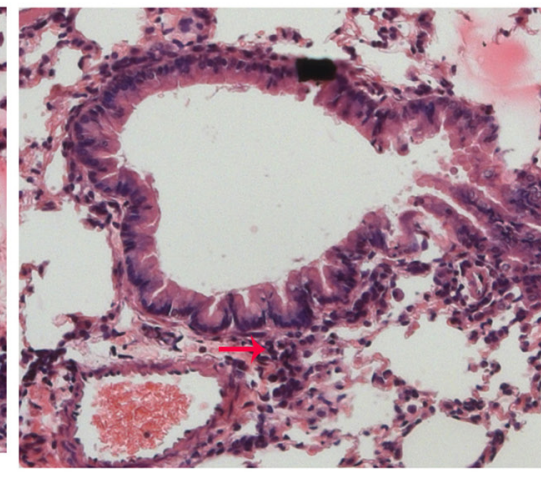

E

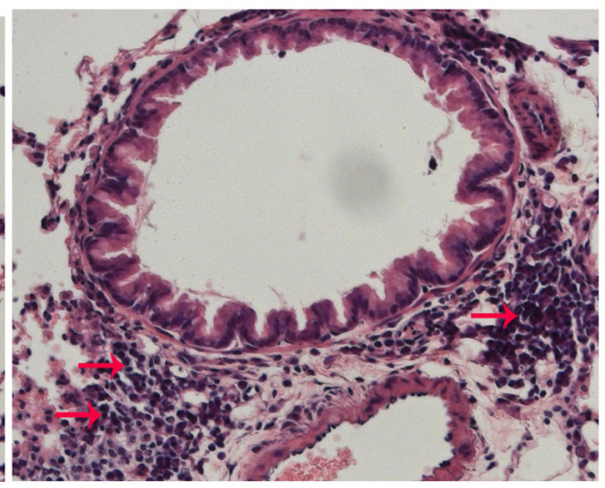

C

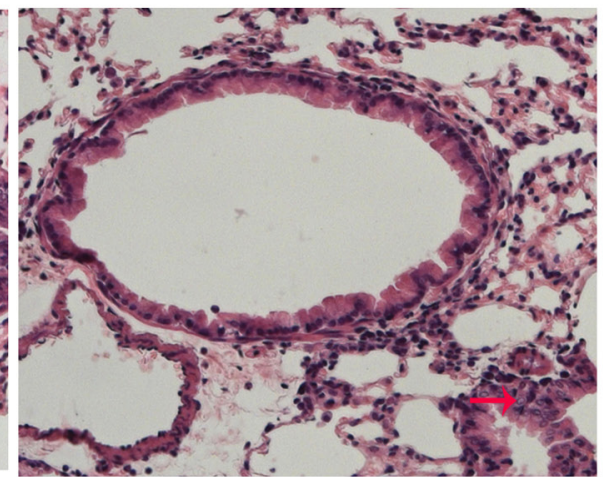

F

Figure 2. LXR-deficient, chronic asthmatic mice display reduced airway inflammation. After the last OVA challenge, lung tissues were fixed, sectioned and stained with H\&E. The inflammatory cells around the airways and vessels were observed by pathologists (red arrows). Representative images for the (A) Control group, (B) OVA group, (C) GW3965 group, (D) LXR $\alpha^{-/}$group, (E) LXR $\beta^{-/}$group and (F) LXR $\alpha / \beta$ KO group (magnification, x200). LXR, liver $\mathrm{X}$ receptor; OVA, ovalbumin; KO, knockout.

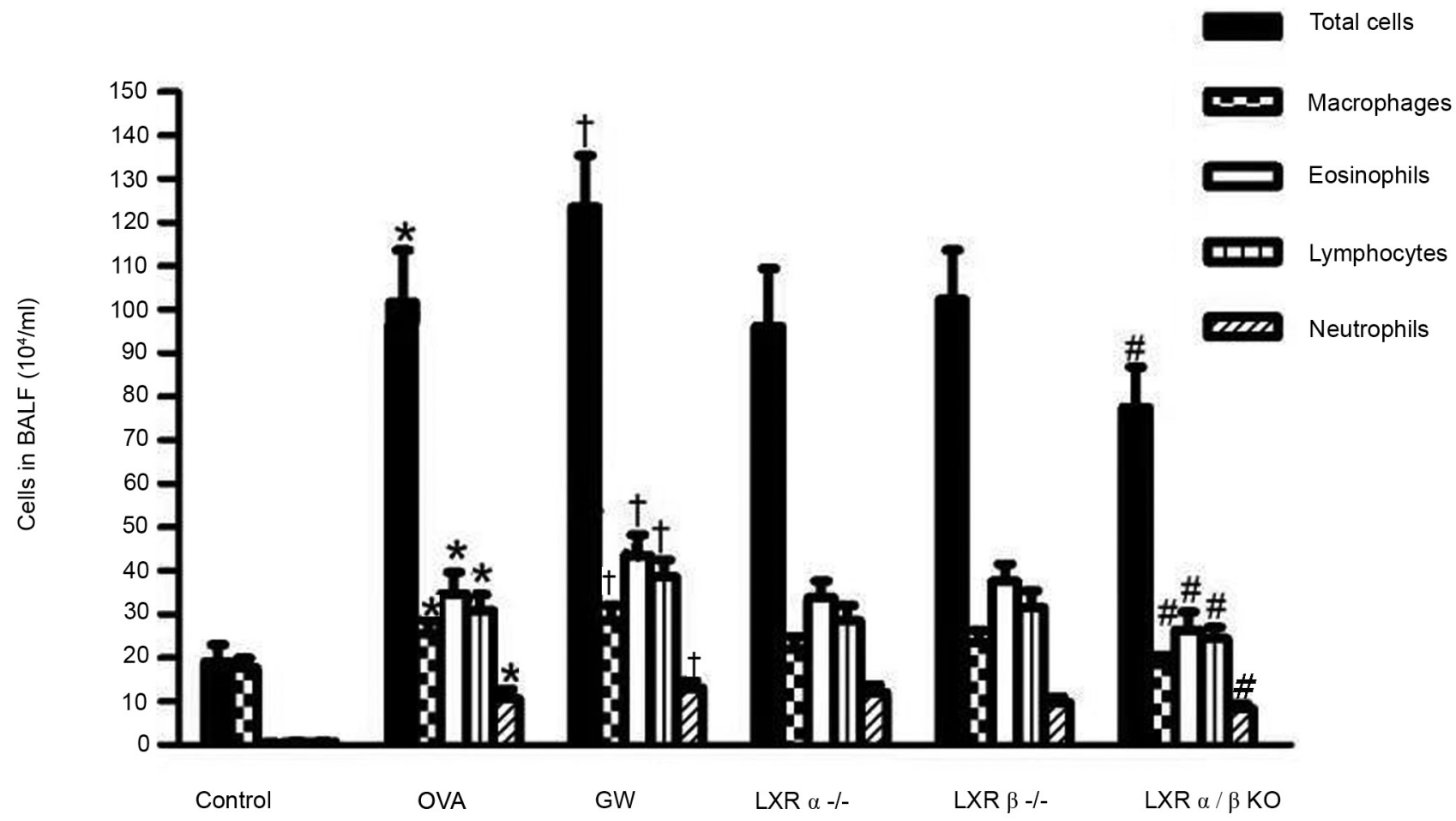

Figure 3. LXR-deficient, chronic asthmatic mice have a reduced number of inflammatory cells in the BALF. Cells were isolated via centrifugation from the BALF and were subjected to Wright-Giemsa staining. Cell numbers and cell differentiation were determined using a hemocytometer $(\geq 200$ cells were counted). " $\mathrm{P}<0.05$ OVA group vs. control group; ${ }^{\mathrm{T}} \mathrm{P}<0.05 \mathrm{GW} 3965$ group vs. OVA group; ${ }^{\text {}} \mathrm{P}<0.05$ LXR-deficient groups vs. OVA group. LXR, liver $\mathrm{X}$ receptor; OVA, ovalbumin; BALF, bronchoalveolar lavage fluid; KO, knockout; GW, GW3965 group. 
A

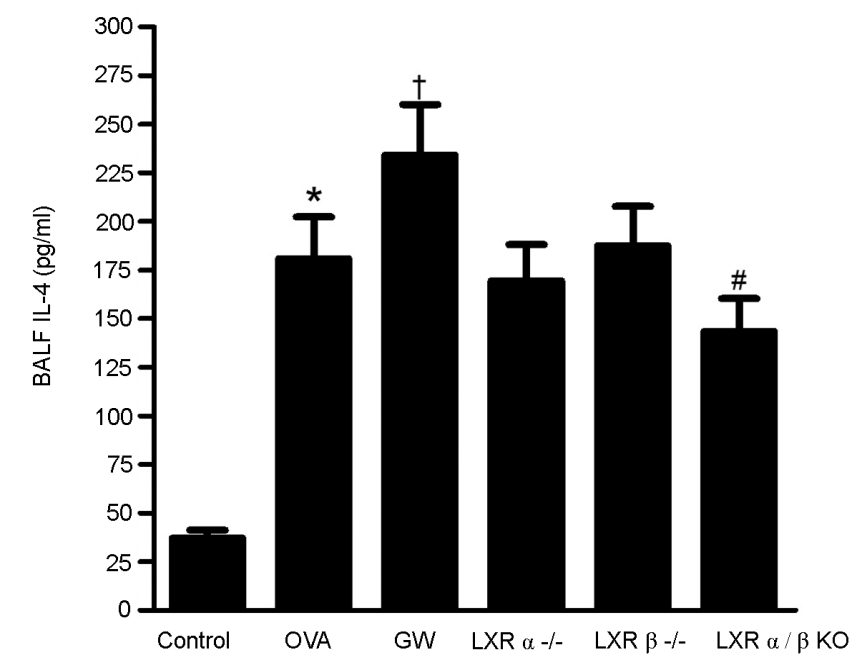

C

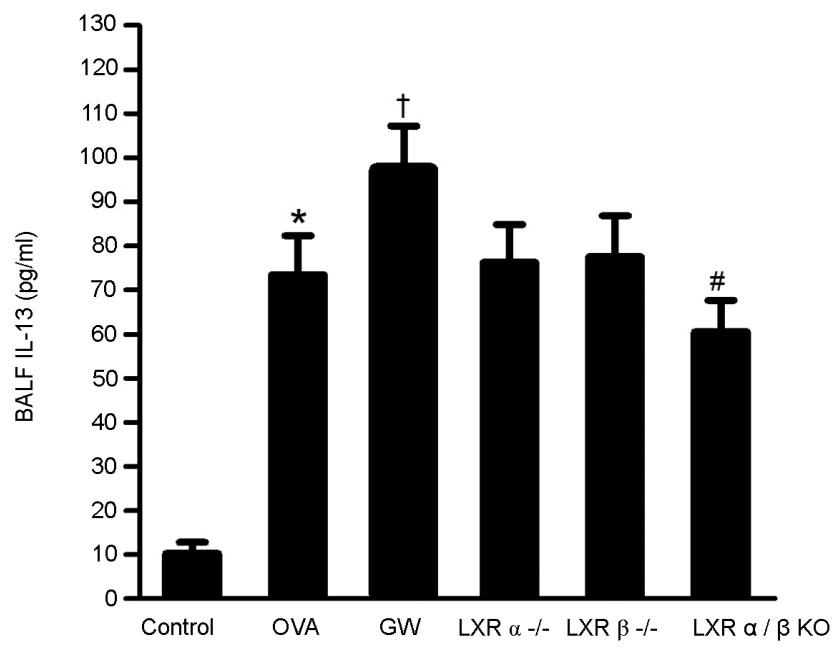

B

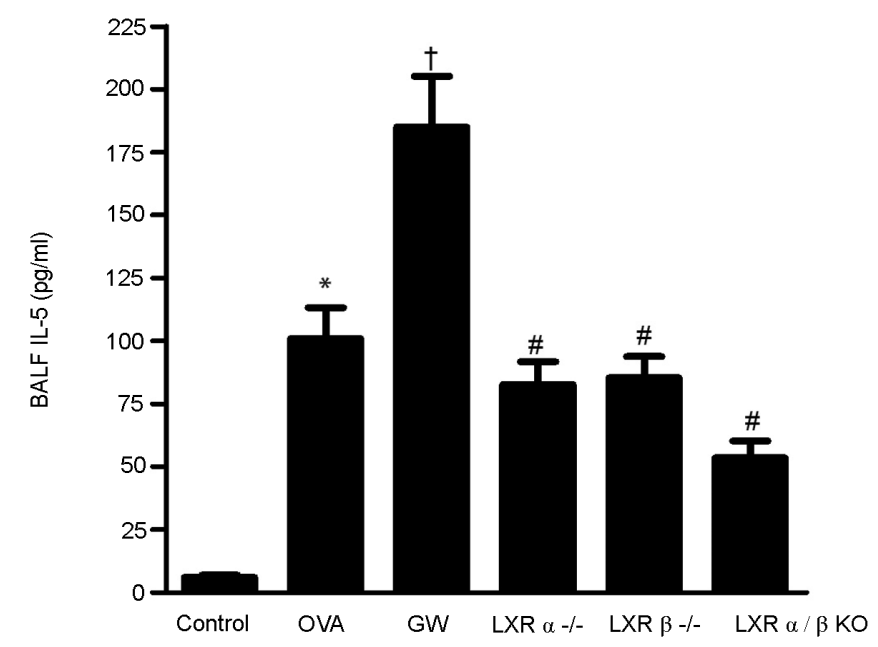

D

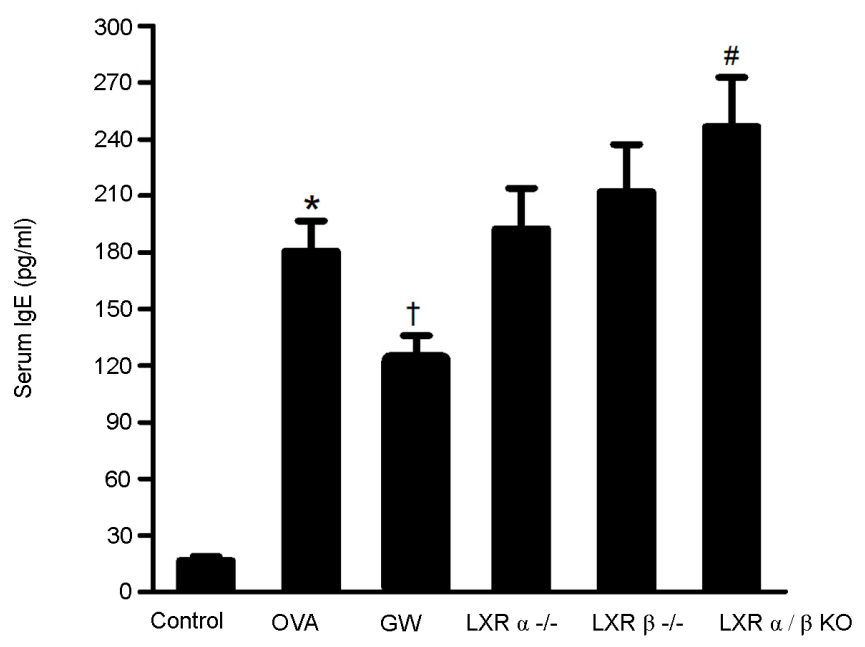

Figure 4. Effect of LXRs on IL-4, IL-5 and IL-13 levels in the BALF and IgE levels in serum from a chronic mouse model of asthma. The levels of (A) IL-4, (B) IL-5 and (C) IL-13 in the BALF and (D) the levels of IgE in serum were quantified using ELISA. "P<0.05 OVA group vs. control group; ${ }^{\mathrm{P}}<0.05 \mathrm{GW} 3965$ group vs. OVA group; ${ }^{*} \mathrm{P}<0.05 \mathrm{LXR}$-deficient groups vs. OVA group. LXR, liver X receptor; OVA, ovalbumin; IgE, immunoglobulin E; BALF, bronchoalveolar lavage fluid; KO, knockout; GW, GW3965 group.

group, while the number of PAS-positive goblet cells was markedly increased in the OVA group and further increased in the GW3965 group. In addition, the number of PAS-positive goblet cells was significantly lower in the LXR $\alpha / \beta$ KO group compared with that in the OVA group.

The effect of the LXR agonist GW3965 on the area of collagen deposition around the duct wall was determined using Masson's trichrome staining analysis of lung tissues (Fig. 6A-G). In the control group, collagen deposition around the airways was minimal. The results demonstrated that the collagen deposition around the airways of mice in the OVA group was significantly increased compared with that in the control group $(\mathrm{P}<0.05)$. In addition, compared with that in the OVA group, the collagen deposition area was increased in the GW3965 group $(\mathrm{P}<0.05)$, while this area was decreased in the $\mathrm{LXR} \alpha / \beta$ KO group $(\mathrm{P}<0.05)$.

The results further demonstrated that $\alpha$-SMA expression was increased in the peribronchiolar region of OVA-challenged mice compared with that in control mice. In addition, administration of GW3965 markedly increased the area of the
$\alpha$-SMA-stained smooth muscle layer compared with that in the OVA group. However, the area of smooth muscle layer stained with $\alpha$-SMA was reduced in the LXR $\alpha / \beta$ KO group as compared with that in the OVA group (Fig. 7A-G). These results indicated that LXRs maypromote airway remodeling.

\section{Discussion}

The present study investigated the effect of LXRs on the pathophysiology of asthma by establishing an LXR-deficient mouse model of chronic allergic asthma. The influence of LXRs on the pathophysiological process of chronic asthma was comprehensively evaluated by detecting airway inflammation, airway hyperreactivity and airway remodeling.

The synthetic agonist used in the present study was GW3965, which is a highly LXR-specific ligand. GW3965 increased the eosinophilic airway inflammation by inducing high secretory levels of Th2 cytokines. A previous study reported that LXR activation is able to directly increase the transcription of IL-5 by improving the promoter activity (23). However, to the best 


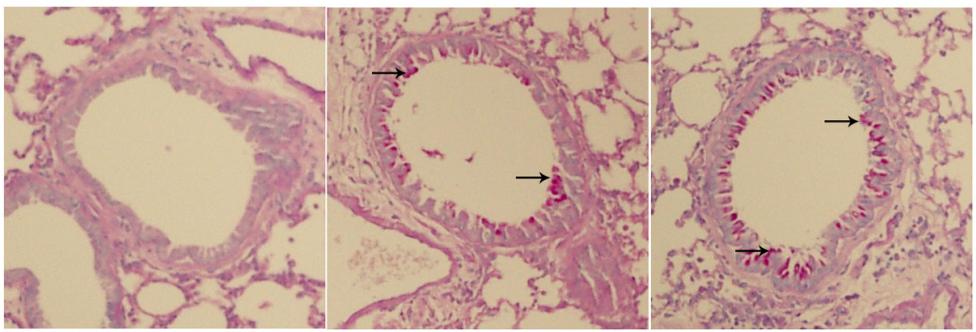

A

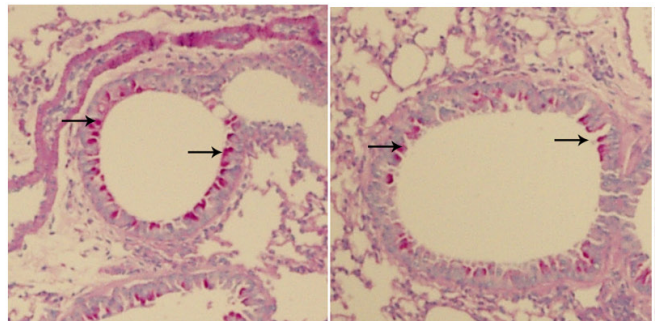

$\mathrm{E}$

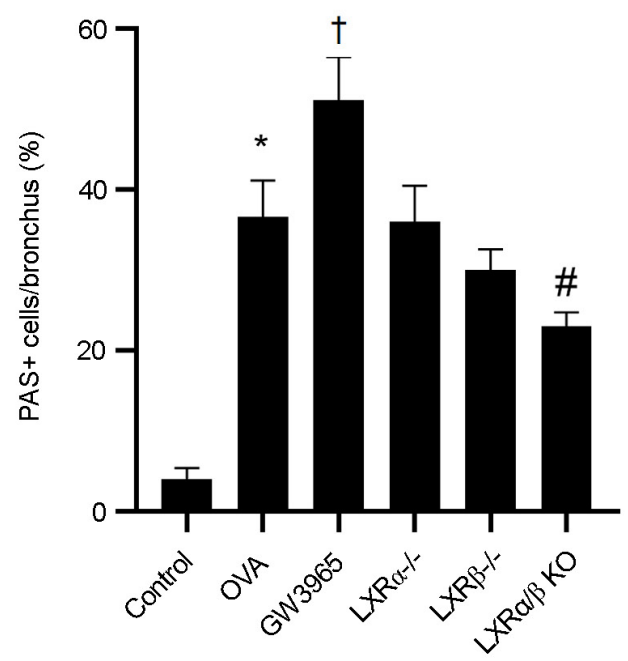

G

Figure 5. LXR-deficient, chronic asthmatic mice have a reduced number of PAS-positive epithelial cells. Lung tissue sections were subjected to PAS staining to assess mucus production. The numbers of PAS-positive and PAS-negative epithelial cells were counted. Red was indicative of positive PAS staining (black arrows). Representative images of the (A) Control group, (B) OVA group, (C) GW3965 group and (D) LXR $\alpha^{-/-}$group, (E) LXR $\beta^{-1}$ group and (F) LXR $\alpha / \beta$ KO group (magnification, $x 200$ ). (G) Numbers of PAS-positive cells from each group. " $\mathrm{P}<0.05$ OVA group vs. control group; ${ }^{\dagger} \mathrm{P}<0.05 \mathrm{GW} 3965$ group vs. OVA group; "P<0.05 LXR-deficient groups vs. OVA group. LXR, liver X receptor; OVA, ovalbumin; PAS, periodic acid-Schiff; KO, knockout.

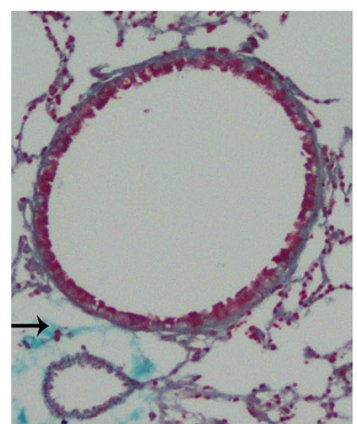

A

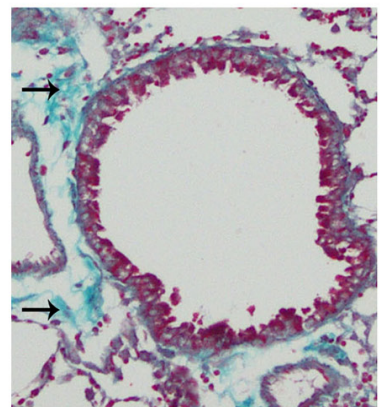

D

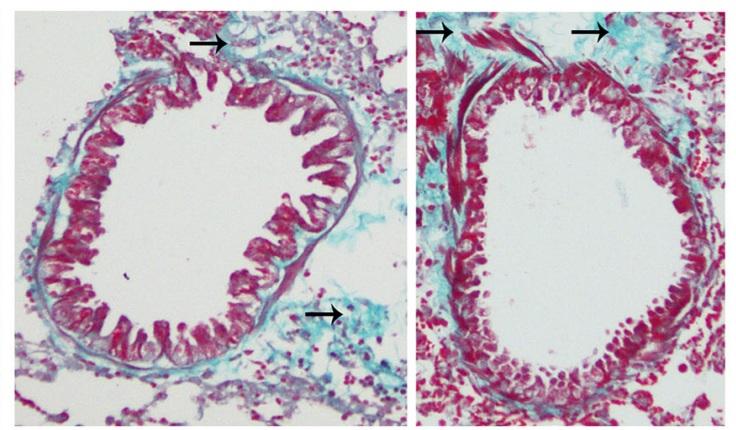

B

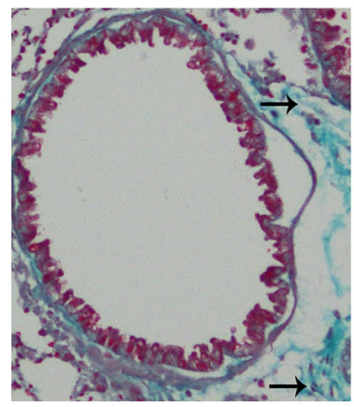

$\mathrm{E}$
C

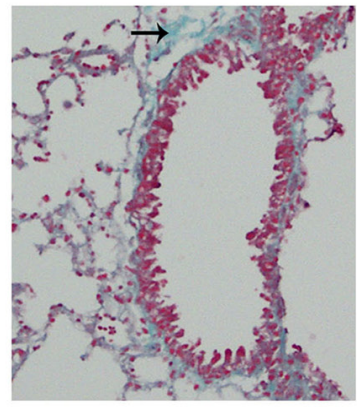

$\mathrm{F}$

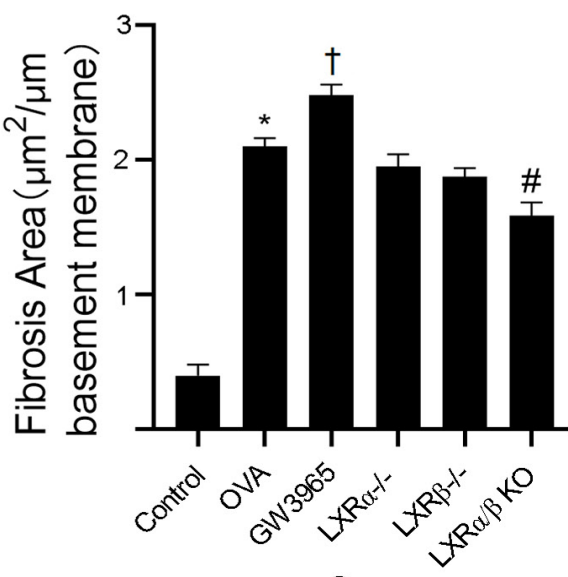

G

Figure 6. LXR-deficient, chronic asthmatic mice have a decreased area of collagen deposition around the duct wall. Masson's Trichrome staining was performed to evaluate subepithelial deposition of collagen. Positive trichrome-stained areas (cyanstained) around the bronchioles and vessels (red stained) were outlined and quantified using Image-Pro Plus 6.0. Representative images for the (A) Control group, (B) OVA group, (C) GW3965 group, (D) LXR $\alpha^{-1}$ group, (E) LXR $\beta^{-1}$ group and (F) LXR $\alpha / \beta$ KO group (magnification, x200). Black arrowsindicate positive trichrome-stained areas around the bronchioles. (G) Fibrotic area for each group. " $\mathrm{P}<0.05$ OVA group vs. control group; ${ }^{\dagger} \mathrm{P}<0.05$ GW3965 group vs. OVA group; ${ }^{*} \mathrm{P}<0.05$ LXR-deficient groups vs. OVA group. LXR, liver $\mathrm{X}$ receptor; OVA, ovalbumin; KO, knockout.

of our knowledge, there are no previous studies suggesting that LXRs are able to increase the transcription of IL- 4 and IL-13. The present study demonstrated that activation of LXRs led to the production of IL- 4 and IL-13 in the airways of model mice with chronic asthma. These results indicated that LXRs may affect $\mathrm{T}$-cell function by increasing the $\mathrm{Th} 2$ cytokine response. 


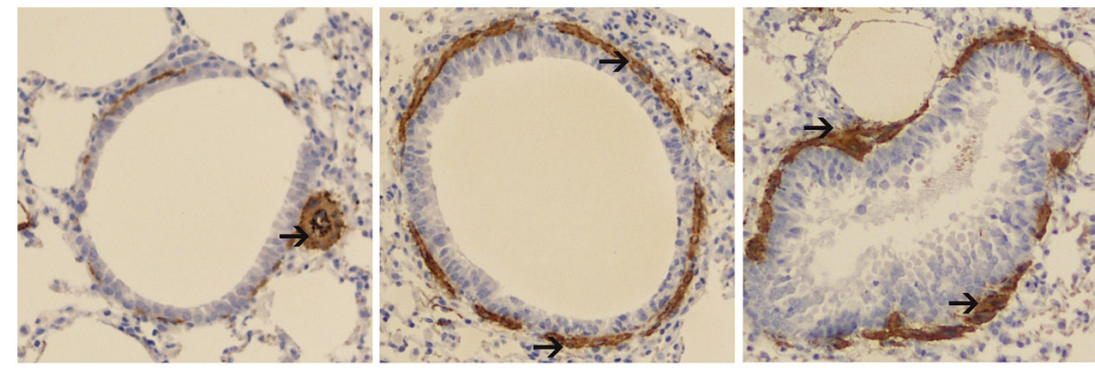

A

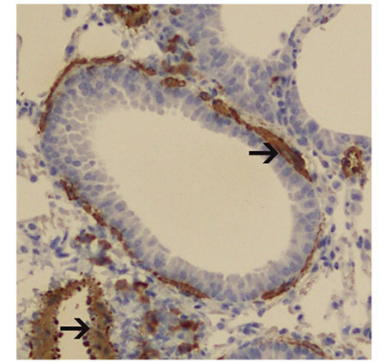

D
B

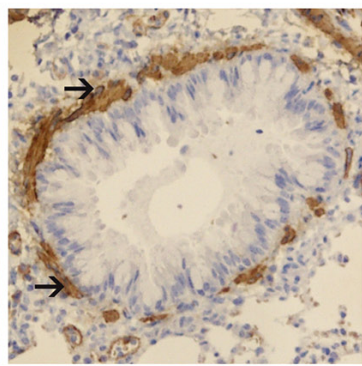

E
C

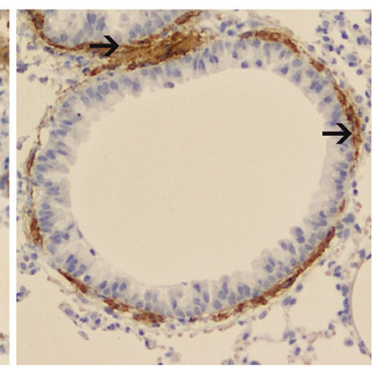

F

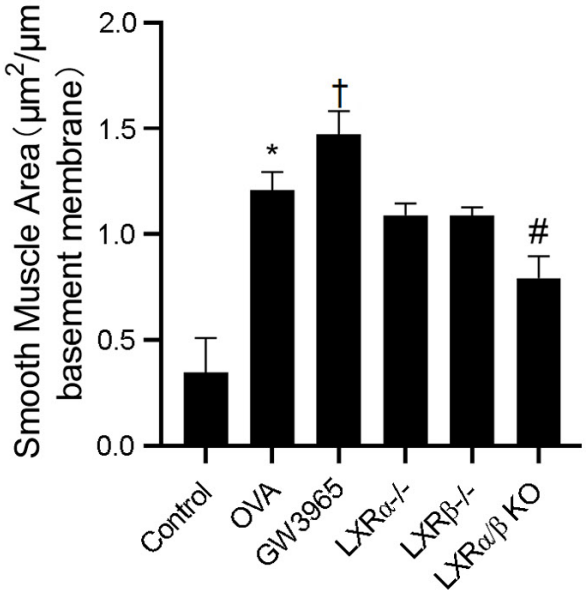

G

Figure 7. LXR-deficient, chronic asthmatic mice have a smaller area of $\alpha$-SMA-stained smooth muscle layer. The area of $\alpha$-SMA-stained smooth muscle layer (brown stained) was examined using immunostaining analysis of lung tissues. Black arrows indicate theimmunostained areas around bronchioles and vessels. Blue stain indicates smooth muscle cells. Representative images for the (A) Control group, (B) OVA group, (C) GW3965 group, (D) LXR $\alpha^{-/-}$group, (E) LXR $\beta^{-/}$ group and (F) LXR $\alpha / \beta$ KO group (magnification, x200). (G) Smooth muscle area for each group. * $\mathrm{P}<0.05$ OVA group vs. control group; ${ }^{\dagger} \mathrm{P}<0.05 \mathrm{GW} 3965$ group vs. OVA group; ${ }^{\#} \mathrm{P}<0.05$ LXR-deficient groups vs. OVA group. LXR, liver X receptor; OVA, ovalbumin; KO, knockout; $\alpha$-SMA, $\alpha$-smooth muscle actin.

An important feature of allergic asthma is the increase in $\operatorname{IgE}$ levels in the serum. IgE-mediated type I allergy is the primary mechanism of the asthma response and leads to airway hyperresponsiveness (24), particularly when asthmatic patients are exposed to allergens. Allergens are captured by antigen-presenting cells and are presented to $\mathrm{T}$ lymphocytes, which is a process that requires a suitable Th2 cytokine environment to enable the B-cell type conversion to a type that produces $\operatorname{IgE}(25-27)$.

Both IL-4 and IL-13 are able to transpose the mRNA of $\mathrm{B}$ cells, thereby causing the transformation of $\mathrm{B}$ cells and the production of IgG4 and IgE with the appropriate co-stimulus signals. The production of $\operatorname{IgE}$ is largely dependent on T-cell synthesis, while basophils and mast cells are able to express CD40 ligand (CD40L), interact with B cells and regulate $\operatorname{IgE}$ synthesis in the absence of endogenous IL-4 and IL-13 (28). Therefore, basophils and mast cells are able to induce IgE syngenesis without $\mathrm{T}$ cells, which is another important pathway for IgE synthesis (29-31). It has been indicated that LXR activation limits anti-CD40 and IL-4-induced differentiation of B cells into IgE-secreting plasmablasts and this may be associated with the reduced phosphorylation of JNK and the increased membrane expression of CD23 (25). In the present study, an appropriate dose of LXR agonist was able to effectively reduce serum IgE levels. On the basis that binding to LXR agonists increased Th2 cytokines, it was suggested that LXR agonists may inhibit IgE production by inhibiting the non-T-cell-dependent pathways and this observation was in line with previous studies $(18,32)$.

Acetylcholine is a type of drug that causes bronchoconstriction and increases airway resistance when inhaled. The present study used different doses of acetylcholine to stimulate the airways. The results demonstrated that LXRs were able to increase airway hyperreactivity. This finding maybe explained by the increase in airway inflammation caused by LXRs.

The specific manifestations of airway remodeling include epithelial injury, hypertrophy of subepithelial fibrous mucous glands, myofibroblast, smooth muscle cell proliferation and angiogenesis (33). In the present study, when comparing the LXR agonist group with the asthma group, the aforementioned changes were more obvious. It was identified that airway remodeling was decreased in $\mathrm{LXR} \alpha / \beta \mathrm{KO}$ mice, which indicated that LXRs promote airway remodeling during chronic asthma. While LXRs were previously indicated to exertanti-proliferative effects on airway smooth muscle in vitro (16), the role of LXRs in mice with chronic asthma appeared to be more complex.

LXRs serve a key role in lipid metabolism and exhibit anti-inflammatory roles in a number of animal models, including those of atherosclerosis and acute lung injury (34). In the present study, it was observed that LXRs aggravated antigen-induced eosinophilic airway inflammation in mice with chronic asthma. However, asthma is a heterogeneous disease with multiple phenotypes (1), and there are numerous non-allergic asthmatic patients with neutrophilic airway inflammation $(1,35)$. It is suggested that LXRs may have favorable inhibitory effects on airway inflammation in non-allergic asthma; however, further research is required.

In conclusion, the present study demonstrated that LXRs promote airway remodeling in allergic chronic asthma and this may be a promising target for allergic asthma treatment. Inhibition of LXR overactivation mayreduce allergic airway inflammation and airway hyperresponsiveness, as well as 
decrease airway remodeling. Therefore, inhibiting LXRs may be a potential treatment for allergic asthma.

\section{Acknowledgements}

Not applicable.

\section{Funding}

The study was supported by the Nanjing Medical Science and Technique Development Foundation (grant no. JQX16028).

\section{Availability of data and materials}

The datasets used and/or analyzed during the current study are available from the corresponding author on reasonable request.

\section{Authors' contributions}

YS, LY and WG designed the experiments. JZ, ZW and FY performed the experiments. JZ, FY and LW collected and analyzed data. ZW and FY sacrificed mice and performed the ELISAs. FY and YT took samples and performed immunohistochemistry. JZ and YT checked and approved the authenticity of all the raw data. The manuscript was written by JZ and YS. All authors read and approved the final manuscript.

\section{Ethics approval and consent to participate}

The present experiment was approved by The Institutional Animal Care and Use Committee of Nanjing First Hospital Affiliated to Nanjing Medical University Animal Center.

\section{Patient consent for publication}

Not applicable.

\section{Competing interests}

The authors declare that they have no competing interests.

\section{References}

1. Boonpiyathad T, Sözener ZC, Satitsuksanoa P and Akdis CA: Immunologic mechanisms in asthma. Semin Immunol 46 101333, 2019

2. Insuela DBR, Ferrero MR, Coutinho DS, Martins MA and Carvalho VF: Could arachidonic acid-derived pro-resolving mediators be a new therapeutic strategy for asthma therapy? Front Immunol 11: 580-598, 2020.

3. Holgate ST, Arshad HS, Roberts GC, Howarth PH, Thurner P and Davies DE: A new look at the pathogenesis of asthma. Clin Sci (Lond) 118: 439-450, 2009.

4. Kudo M, Ishigatsubo Y and Aoki I: Pathology of asthma. Front Microbiol 4: 263, 2013.

5. Russell RJ and Brightling C: Pathogenesis of asthma: Implications for precision medicine. Clin Sci (Lond) 131: 1723-1735, 2017.

6. Birrell MA, De Alba J, Catley MC, Hardaker E, Wong S Collins M, Clarke DL, Farrow SN, Willson TM, Collins JL and Belvisi MG: Liver X receptor agonists increase airway reactivity in a model of asthma via increasing airway smooth muscle growth. J Immunol 181: 4265-4271, 2008.

7. Castrillo A and Tontonoz P: Nuclear receptors in macrophage biology: At the crossroads of lipid metabolism and inflammation. Annu Rev Cell Dev Biol 20: 455-480, 2004.
8. Joseph SB, Castrillo A, Laffitte BA, Mangelsdorf DJ and Tontonoz P: Reciprocal regulation of inflammation and lipid metabolism by liver X receptors. Nat Med 9: 213-219, 2003.

9. Castrillo A, Joseph SB, Marathe C, Mangelsdorf DJ and Tontonoz P: Liver X receptor-dependent repression of matrix metalloproteinase-9 expression in macrophages. J Biol Chem 278: 10443-10449, 2003.

10. Smet M, Van Hoecke L, De Beuckelaer A, VanderBeken S, Naessens T, Vergote K, Willart M, Lambrecht BN, Gustafsson JA, Steffensen KR and Grooten J: Cholesterol-sensing liver X receptors stimulate Th2-driven allergic eosinophilic asthma in mice. Immun Inflamm Dis 4: 350-361, 2016.

11. Bruemmer D, Collins AR, Noh G, Wang W, Territo M, Arias-Magallona S, Fishbein MC, Blaschke F, Kintscher U, Graf K, et al: Angiotensin II-accelerated atherosclerosis and aneurysm formation is attenuated in osteopontin-deficient mice. J Clin Invest 112: 1318-1331, 2003.

12. Ogawa D, Stone JF, Takata Y, Blaschke F, Chu VH, Towler DA, Law RE, Hsueh WA and Bruemmer D: Liver x receptor agonists inhibit cytokine-induced osteopontin expression in macrophages through interference with activator protein-1 signaling pathways. Circ Res 96: e59-e67, 2005.

13. Solan PD, Piraino G, Hake PW, Denenberg A, O'Connor M, Lentsch A and Zingarelli B: Liver X receptor $\alpha$ activation with the synthetic ligand T0901317 reduces lung injury and inflammation after hemorrhage and resuscitation via inhibition of the nuclear factor $\kappa$ B pathway. Shock 35: 367-374, 2011.

14. Wang D, Liu M, Wang Y, Luo M, Wang J, Dai C, Yan P, Zhang X, Wang Y, Tang C and Xiao J: Synthetic LXR agonist T0901317 attenuates lipopolysaccharide-induced acute lung injury in rats. Int Immunopharmacol 11: 2098-2103, 2011.

15. August A, Mueller C, Weaver V, Polanco TA, Walsh ER and Cantorna MT: Nutrients, nuclear receptors, inflammation, immunity lipids, PPAR, and allergic asthma. J Nutr 136: 695-699, 2006.

16. Lee KS, Park SJ, Hwang PH, Yi HK, Song CH, Chai OH, Kim JS, Lee MK and Lee YC: PPAR-gamma modulates allergic inflammation through up-regulation of PTEN. FASEB J 19: 1033-1035, 2005.

17. Zelcer $\mathrm{N}$ and Tontonoz P: Liver $\mathrm{X}$ receptors as integrators of metabolic and inflammatory signaling. J Clin Invest 116: 607-614, 2006.

18. Shi Y, Xu X, Tan Y, Mao S, Fang S and Gu W: A liver-X-receptor ligand, T0901317, attenuates IgE production and airway remodeling in chronic asthma model of mice. PLoS One 9: e92668, 2014.

19. Ogawa S, Lozach J, Benner C, Pascual G, Tangirala RK, Westin S, Hoffmann A, Subramaniam S, David M, Rosenfeld MG and Glass CK: Molecular determinants of crosstalk between nuclear receptors and toll-like receptors. Cell 122: 707-721, 2005.

20. Castrillo A, Joseph SB, Marathe C, Mangelsdorf DJ and Tontonoz P: Liver X receptor-dependent repression of matrix metalloproteinase- 9 expression in macrophages. J Biol Chem 278: 10443-10449, 2003.

21. Michael LF, Schkeryantz JM and Burris TP: The pharmacology of LXR. Mini Rev Med Chem 5: 729-740, 2005.

22. Zhao Z, Xu D, Li S, He B, Huang Y, Xu M, Ren S, Li S, Wang $\mathrm{H}$ and $\mathrm{Xie} \mathrm{W}$ : Activation of liver $\mathrm{X}$ receptor attenuates oleic acid-induced acute respiratory distress syndrome. Am J Pathol 186: 2614-2622, 2016.

23. Chen Y, Duan Y, Kang Y, Yang X, Jiang M, Zhang L, Li G, Yin Z, Hu W, Dong P, et al: Activation of liver X receptor induces macrophage interleukin-5 expression. J Biol Chem 287: 43340-43350, 2012.

24. Asayama K, Kobayashi T, D'Alessandro-Gabazza CN, Toda M, Yasuma T, Fujimoto H, Okano T, Saiki H, Takeshita A, Fujiwara K, et al: Protein $S$ protects against allergic bronchial asthma by modulating Th1/Th2 balance. Allergy 75: 2267-2278, 2020.

25. Heine G, Dahten A, Hilt K, Ernst D, Milovanovic M, Hartmann B and Worm M: Liver $X$ receptors control IgE expression in B cells. J Immunol 182: 5276-5282, 2009.

26. Nunomura S, Endo K, Makishima M and Ra C: Oxysterol represses high-affinity IgE receptor-stimulated mast cell activation in Liver X receptor-dependent and -independent manners. FEBS Lett 584: 1143-1148, 2010.

27. Gould HJ and Sutton BJ: IgE in allergy and asthma today. Nat Rev Immunol 8: 205-217, 2008.

28. Jabara HH, Fu SM, Geha RS and Vercelli D: CD40 and IgE: Synergism between anti-CD40 monoclonal antibody and interleukin 4 in the induction of $\operatorname{IgE}$ synthesis by highly purified human B cells. J Exp Med 172: 1861-1864, 1990. 
29. Lala DS: The liver X receptors. Curr Opin Investig 6: 934-943, 2005.

30. Tontonoz P and Mangelsdorf DJ: Liver X receptor signaling pathways in cardiovascular disease. Mol Endocrinol 17: 985-993, 2003.

31. Chen S, Sims GP, Chen XX, Gu YY, Chen S and Lipsky PE: Modulatory effects of 1,25-dihydroxyvitamin D3 on human B cell differentiation. J Immunol 179: 1634-1647, 2007.

32. Hatano Y, Man MQ, Uchida Y, Crumrine D, Mauro TM, Feingold KR, Elias PM and Holleran WM: Murine atopic dermatitis responds to peroxisome proliferator-activated receptors alpha and beta/delta (but not gamma) and liver $\mathrm{X}$ receptor activators. J Allergy Clin Immunol 125: 160-169.e1-e5, 2010.

33. Delvecchio CJ, Bilan P, Radford K, Stephen J, Trigatti BL, Cox G, Parameswaran K and Capone JP: Liver X receptor stimulates cholesterol efflux and inhibits expression of proinflammatory mediators in human airway smooth muscle cells. Mol Endocrinol 21: 1324-1334, 2007.
34. Zhao L, Lei W, Deng C, Wu Z, Sun M, Jin Z, Song Y, Yang Z, Jiang $S$, Shen $M$ and Yang $Y$ : The roles of liver X receptor $\alpha$ in inflammation and inflammation-associated diseases. J Cell Physiol 36: 4807-4828, 2021.

35. Hanashiro J, Muraosa Y, Toyotome T, Hirose K, Watanabe A and Kamei K: Schizophyllum commune induces IL-17-mediated neutrophilic airway inflammation in OVA-induced asthma model mice. Sci Rep 9: 19321, 2019.

(i) $(9)$ This work is licensed under a Creative Commons Attribution-NonCommercial-NoDerivatives 4.0 International (CC BY-NC-ND 4.0) License. 